\title{
Study of Serum Ferritin and Glycated Hemoglobin in Type 2 Diabetes Mellitus
}

\author{
Tanveer Ahmed ${ }^{1}$ \\ ${ }^{1}$ Assistant Professor, Department of General Medicine, Navodaya Medical College, Raichur, Karnataka.
}

\section{Abstract}

Background: Type 2 diabetes mellitus is a common metabolic disorder of multiple etiologies. Increased levels of serum ferritin have been indicated to be associated with the etiology of the diabetic process, as well as in pathogenesis of various diabetic complications. The study aims to understand the relationship between the serum ferritin and glycated hemoglobin in type 2 diabetes mellitus. Subjects and Methods: The study was conducted at Medical College Hospital and Research Centre. A total of hundred cases of type 2 diabetes mellitus of the age group 30 -70 years were taken for the study after satisfying the inclusion and exclusion criteria. Hundred healthy volunteers in the age group $30-70$ years, sex matched during the same period was included in the study under the control group. Results: Serum ferritin level was significantly high in cases compared to controls. There was moderate correlation between serum ferritin and glycated hemoglobin. There was significant increase in serum ferritin levels in type 2 diabetics compared to the controls. There was a moderate correlation between serum ferritin and glycated hemoglobin. Conclusion: This study explores the possibility of finding serum ferritin as a marker to explain the oxidative stress process in type 2 diabetes mellitus. This valuable information would be helpful in proper medical intervention.

Keywords: Type 2 diabetes mellitus, Serum ferritin, Glycated hemoglobin.

Corresponding Author: Dr. Tanveer Ahmed, Assistant Professor, Department of General Medicine, Navodaya Medical College, Raichur, Karnataka.

Received: October 2019

Accepted: October 2019

\section{Introduction}

The term diabetes mellitus derived from the Greek words dia (through), bainein (to go) and mellitus (sweet). Diabetes mellitus (DM) means the urine of the patient contains sugar. ${ }^{[1]}$ The best early evidence of a description of the symptoms of diabetes in the world literature is recorded in the Ebers Papyrus that appears to date from 1550 B.C. This links the description of polyuria to Imhotep, a man of medicine, architecture and magic who was high priest and minister to Pharaoh Zosser in 3000 B.C. Arateus in his work acute and chronic diseases, coined the term diabetes meaning _siphon', to explain the liquefaction of the flesh and bones in urine.

Diabetes mellitus is the most common endocrine disease. It is described as a group of metabolic disorders of multiple etiologies characterized by chronic hyperglycemia associated with disturbances of carbohydrate, fat and protein metabolism due to absolute or relative deficiency of insulin secretion and / or action. ${ }^{[2]}$

The symptoms related to hyperglycemia are polyuria, polydipsia, polyphagia associated with weight loss but may not be present in a sizeable proportion of the cases. This disorder is associated with significant long term sequels, particularly damage or dysfunction of various organs especially kidneys, eyes, nerves, heart and blood vessels. ${ }^{[3]}$
Chronic hyperglycemia in type 2 DM leads to oxidative stress created by an imbalance of pro-oxidants, involves glucose auto-oxidation, protein glycation, polyol pathway and over production of superoxide radicals which causes oxidative stress.

This oxidative stress leads to complications in type $2 \mathrm{DM}$. The long term hyperglycemic status favoursglycation reactions leading to formation of advanced glycated end products (AGE). This causes tissue damage by cross linking of collagen. Therefore complications in type $2 \mathrm{DM}$ are dependent on glycemic control. ${ }^{[4]}$

Iron is present in almost all cells of the body. About $75 \%$ of total iron is hemoglobin $(\mathrm{Hb}), 5 \%$ is in myoglobin and $15 \%$ in ferritin. Ferritin is ubiquitous intra cellular protein that stores iron and releases it in controlled fashion. It acts as a buffer against iron deficiency and iron overload. ${ }^{[5]}$

The relationship between iron metabolism and type $2 \mathrm{DM}$ is bi-directional.Iron influences glucose metabolism, even in the absence of significant iron overload.Iron is a potent prooxidant that increases cell oxidative stress causing inhibition of insulin internalization and actions, resulting in hyperinsulinemia and insulin resistance. Free iron exerts a positive feedback on ferritin synthesis and oxidative stress increases the release of iron from ferritin. ${ }^{[6]}$

The abnormalities in ferritin metabolism following glycation in hyperglycemic state might be a primary cause of hyperferritinaemia in type $2 \mathrm{DM}$. Glycated ferritin has longer 
half-life. Glycation of transferrin decreases its ability to bind ferrous ion and by increasing the pool of free iron and stimulates ferritin synthesis.

Thus, type $2 \mathrm{DM}$ is associated with abnormalities of ferritin metabolism resulting in parallel increase of serum ferritin levels.

In this study estimation of serum ferritin will be carried out in patients with type 2 diabetes mellitus and a correlation of these values with the glycated hemoglobin will be studied. Hence we are exploring the possibility of using serum ferritin for screening persons at high risk of diabetic complications.

\section{Subjects and Methods}

Hundred patients of type 2 diabetes mellitus between age group of 30-70 years attending General Medicine OPD, Medical College and Hospital, were included in the study. Also hundred healthy volunteers in the age group 30-70 years, sex matched during the same period were included in the study under the control group.

\section{Inclusion Criteria}

Hundred subjects of type 2 diabetes mellitus between age group of 30-70 years attending general medicine OPD at Medical College and Hospital

\section{Exclusion Criteria}

- $\quad$ Type 1 diabetes mellitus

- Other states associated with altered serum ferritin levels like-o Hemochromatosis

- Chronic alcoholics

- Chronic inflammatory condition like SLE, rheumatoid arthritis o Hepatitis, pancreatitis

- Patients with repeated blood transfusions o Iron deficiency anemia

- Hypothyroidism

- History Of Iron Supplimentation, pregnancy.

\section{Method of collection of data}

A pre-structured and pre-tested proforma was used to collect the data. Informed consent was taken from all cases and control subjects. Base line data including age and sex, detailed medical history including conventional risk factors, clinical examinations and relevant investigations were included as part of the methodology.

For blood investigations, $5 \mathrm{ml}$ of blood was collected under aseptic precautions from selected subjects on overnight fasting of 12 hours.

Fasting and 2 hours postprandial blood sample were collected for the analysis in the below mentioned vacuum evacuated tubes.

- Fluoride EDTA vacuum evacuated tubes for estimation of blood glucose and glycated hemoglobin.

- Clot activator vacuum evacuated tubes for estimation of serum ferritin.

- Serum obtained following centrifugation was used for estimation of serum ferritin.

- Fresh random mid stream urine sample was collected in a sterile container for estimation of micro albumin.

\section{Results}

A total of 72 cases admitted to our hospital between Jan 2017 to Dec 2018 were statically analyzed. Most of the dengue cases presented during the month of August and September which depicts the role of rainy season for case clustering during that season.

Table 1(a): Comparison of HbA1c in study group
\begin{tabular}{|l|l|l|l|l|l|l|}
\hline \multirow{2}{*}{ HbA1C } & Cases & \multicolumn{2}{l}{ Controls } & \multirow{2}{*}{ Total } \\
\cline { 3 - 7 } & No & $\%$ & No & \% & \\
\hline \multirow{3}{*}{ HbA1C } & $<6$ & 0 & 0 & 100 & 100 & 100 \\
\cline { 2 - 7 } & $6-8$ & 71 & 71 & 0 & 0 & 71 \\
\cline { 2 - 7 } & $>8$ & 29 & 29 & 0 & 0 & 29 \\
\hline \multicolumn{2}{|l|}{ Total } & 100 & 100 & 100 & 100 & 200 \\
\hline
\end{tabular}

Table 1(b): Comparison of HbA1c in study group

\begin{tabular}{|l|l|l|l|}
\hline HbA1c & Mean & SD & P Value \\
\hline Cases & 7.56 & 0.86 & $0.000<0.001^{* *}$ \\
\hline Controls & 5.22 & 0.278 & Extremely Significant \\
\hline
\end{tabular}

Table 2: Comparison of Serum ferritin levels in study group

\begin{tabular}{|l|l|l|l|}
\hline Parameters & Cases & Controls & P Value \\
\hline FBS & 146.94 & 86.71 & $0.000<0.001^{* *}$ \\
\hline Serum Ferritin ng/ml & 177.45 & 53.82 & $0.000<0.001^{* *}$ \\
\hline
\end{tabular}

The mean serum ferritin level among cases was $177.45 \pm 111.98 \mathrm{ng} / \mathrm{ml}$ as compared to $53.82 \pm 35.73 \mathrm{ng} / \mathrm{ml}$ among controls. There was significant difference in serum ferritin levels among cases and controls.

Table 3: Pearson correlation of Serum Ferritin ng/ml with FBS (mg/dl), PBS (mg/dl), and HbA1c\%

\begin{tabular}{|l|l|l|l|l|}
\hline \multirow{2}{*}{ Pair } & \multicolumn{2}{|c|}{ Cases } & \multicolumn{2}{c|}{ Cases } \\
\cline { 2 - 5 } & r Value & p Value & r Value & $\begin{array}{l}\text { p } \\
\text { Value }\end{array}$ \\
\hline $\begin{array}{l}\text { Serum Ferritin } \\
\text { ng/ml vs FBS } \\
(\mathrm{mg} / \mathrm{dl}),\end{array}$ & 0.130 & 0.198 & 0.068 & 0.638 \\
\hline $\begin{array}{l}\text { Serum Ferritin } \\
\text { ng/ml vs. PPBS } \\
(\mathrm{mg} / \mathrm{dl}),\end{array}$ & 0.097 & 0.338 & 0.018 & 0.899 \\
\hline $\begin{array}{l}\text { Serum Ferritin } \\
\text { ng/ml vs HbA1c\% }\end{array}$ & 0.274 & $\mathbf{0 . 0 0 0 < 0 . 0 0 6 * *}$ & 0.109 & 0.452 \\
\hline
\end{tabular}

In the present study, there is a increased serum ferritin level in diabetes mellitus compared to healthy controls. There is moderate correlation between serumferritin levels and Glycated hemoglobin in cases. The data is entered in excel spreadsheet and statistically analyzed using SPSS software. The tests like Chi-Square, t-tests etc are applied to analyze the data.

Descriptive statistical analysis has been carried out in the present study. Chi square and Fisher extract has been used to find significance of proportion of serum ferritin levels between cases and controls. Student ' $t^{\text {t} t e s t ~ h a s ~ b e e n ~ u s e d ~ t o ~}$ find the significance of serum ferritin level between cases/controls.

\section{Discussion}

The role of iron in the pathogenesis of diabetes mellitus is, iron is a potent pro oxidant and reactive oxygen species have been shown to interfere with insulin signaling at the cellular 
level. Iron is a catalyst in formation of hydroxyl radicals, which are powerful pro oxidants attack cellular membrane lipids, proteins andnucleic acids contributes to insulin resistance initially and subsequently to the development of type $2 \mathrm{DM}$.

The central importance of iron in the pathophysiology of disease is derived because of the ease with which iron is reversibly oxidized and reduced. This property, which is essential for its metabolic functions, makes iron potentially hazardous from its ability to participate in the generation of powerful oxidant species such as hydroxyl radicals. ${ }^{[7]}$

Because iron participates in the formation of reactive oxygen species, organisms take care in the handling of iron and indeed, iron sequestration in transport and storage proteins may contribute to antioxidant defenses.

It is now well established that oxidants can cause release of catalytic iron, thus interacting a vicious cycle that leads to the formation of more reactive species.

The major aspect of treatment of type 2 diabetes mellitus is the requirement of sensitive serum markers that are associated with the disease. So early diagnosis and medical interventions can delay or diminish the morbidity associated with type 2 diabetes mellitus.

Fernandez real $\mathrm{J} \mathrm{M}$ et al in their study have shown hyper feritininemia is present in $6.6 \%$ of type 2 diabetics, serum concentrations of ferritin areusually increased in poorly controlled type 1 and type 2 diabetes subjects and ferritin has been shown predict $\mathrm{HbA}_{1} \mathrm{c}$ independently of glucose, probably reflecting increased oxidative stress. Short term improvement inglycemic control is followed by variable decreases in serum ferritin concentration. ${ }^{[8]}$ Some studies suggest that free radical formation may play a role by disrupting insulin action and total body glucose disposal. The facts that oxidative stress is increased in glucose intolerance suggests possible mechanisms for iron's action. ${ }^{[9]}$ In Earl S Ford et al study, serum ferritin concentration was significantlyassociated with newly diagnosed diabetes and association was stronger in men than in women. ${ }^{[10]}$

Nan heekim et al study shows that serum ferritin concentration was significantly correlated with fasting cpeptide in type 2 diabetes patients and was significantly correlated with fasting sugar level in the control group. So serum ferritin would be a marker of not only glucose homeostasis but also some components of insulin resistance syndrome in both diabetic and control subjects. ${ }^{[1]}$

Van ost BA, VandenBeld B study gave the explanation, that delayed clearance of glycosylated ferritin in participants with diabetes may have lead to elevated ferritin concentration. ${ }^{[12]}$

Swaminathan et al findings, indicate that ferritin is associated with a greater frequency of IFG or diabetes only among those with high normal Gama-GlutamylTransferase (GGT), not in those with low normal GGT and suggested ferritin as a factor for development IFG/Diabetes. The association between increased GGT and glucose intolerance might be explained by some underlying, biological mechanisms such as enhanced oxidative stress, insulin resistance and fatty liver. ${ }^{[13]}$

Dymock M W J C et al and Facchini F S et al support that phlebotomy is followed by drop in serum glucose, serum cholesterol, serum triglycerides and improvement in both beta cell secretion and peripheral insulin action in type 2 diabetes mellitus and serum ferritin values significantly decreased. ${ }^{[14]}$

Jehn et al, argue that the modest elevations in ferritin levels observed in diabetes may be a consequence or marker rather than the cause of impending insulin resistance and that elevated ferritin may not reflect elevated body iron stores or an intracellular labile iron pool that participates in oxidant injury. ${ }^{[15]}$

In our study we also observed serum ferritin moderately correlated with glycated hemoglobin. This may be due to abnormalities in ferritin metabolism following glycation in a hyperglycemic state. Glycosylated ferritin has a longer serum half life. Glycemic control itself influences serum ferritin concentrations.

Derangement in serum parameters of iron metabolism are frequently found in patients with poorly controlled diabetes mellitus. In patients with increased serum ferritin, glycemic control is poor and there isvascular damage.

Jeevan K Shetty et al estimated free iron, both ferrous and ferric form, protein thiols, lipid hydroperoxides, fasting blood glucose, HbA1c and serum ferritin levels in serum. There was a significant increase in free iron in $\mathrm{Fe}^{+3}$ state $(\mathrm{P}<0.01), \quad \mathrm{HbA}_{1 \mathrm{c}} \quad(\mathrm{P}<0.01) \quad$ serum ferritin $\quad(\mathrm{P}<0.01)$, lipidhydroperoxides $(\mathrm{P}<0.01)$ in diabetics with poor glyceimic control compared to diabetics cases with good glyceimic control and healthy controls. ${ }^{[16]}$

In trial by Cantur $\mathrm{K} \mathrm{Z}$ et al, poorly controlled patients of diabetes had hyper ferritinemia. This confirmed that serum ferritin was increased in diabetics as long as glycemic control was not achieved. Serum ferritin concentration and concentrations of insulin, glucose and glycosylatedhemoglobin were significantly raised in both men and women. ${ }^{[10]}$ Recently some studies have investigated the effect of chelator agents such as desferoxamine on the control of diabetes mellitus. There are different results in this regard. Some studies have determined a higher level of ferritin in people who are high risk for atherosclerosis. Insulin resistance has been considered as the basic factor in the pathogenesis of atherosclerosis.

\section{Conclusion}

This study explores the possibility of utility of serum ferritin as a marker of the oxidative stress process in diabetics. This valuable information would be helpful in proper medical intervention.

\section{References}

1. Mann N, W D, Dudman N, - The effect of diet on plasma hommolysteine concentration in healthy male subjectsll. EurJuin NUTV, 2000. 71:682-692.

2. Roselti L, Rothman D L, - The effect of dietary protein on in vivo insulin action and liver glycogen repletionll. Am J Physiol, 1989,257: E212-E219.

3. Mac Donald MJ, Cook JD, - Large amount ferritin in the pancreatic insulin cell and its stimulation by glucosell FASEB J 1994,8 : 777 781.

4. Rahier J R, Loozen S, Goebbels RM, - The homochromatic human pancreas immunohistochemical and ultra structural studyll. Diabetelogia 1987, $30: 5-12$

5. Bertelson M, Anggard EE, Carrier MJ, -Oxidative stress impairs insulin internalization in endothelial cells vivoll. Diabchologia 2001, 44:605-613.

6. Reif DW, - Ferrritin as a source of iron for oxidative damagell. Free Rad Biol Med 1992, 12 :417-427. 
7. Jose Manuel Fernandez-Real, Abel Lopez-Berme-jo, and Ricart. 2002. Perspectives in diabetes: cross talk between iron metabolism and diabetesll. Diabetes - vol15:2348-2354.

8. Fernandez-Real JM Ricat W, Amoyo E, -Serum ferritin as a component of the insulin resistance syndromell Diabetes care 1998, 21:62-68.

9. Wannamethee SG. Perny IJ, Shaper AG, - Hematocrit and risk of NIPPM.Diabetes 1996, 45: 576-579.

10. Earls, Ford, Mary E, Logs Well, -Diabetes and serum ferritin concentration among US Adultsll. Diabetes care, 1999; 22(12): 19781983.

11. Kim Hee Nan., et Al., 2000. - Serum ferritin in healthy subjects and type 2 diabetic patientsl. Yonsei Medical Journal. 41(3):387-392.

12. Van ost BA, VandenBeld B, - Measurement of ferritin in serum application in diagnostic usell, clinBiochem, $1984 ; 17: 263-269$.

13. SundararamanSwaminathan, Visian A, Sudhir V, - The role of iron in diabetes and its complicationsll. Diabetes care, 2007; 28: 1-20.

14. Dymock MWJC, Payke DA, Oakley WG, Roger William, -Observations as the pathogenesis complications and treatment of diabetes, 115 cases of hemochromatosisll. American J Medicine, 1972; 203-209.

15. Jehn ML, Guallar E, Clark JM, -A prospective study of plasma ferritin level and incident diabetes : the atheroscelosis risk in communities.[ARIC] studyll, Am J epidemiol 2007 ; 165 : 1047-1054

16. Jeeven K. Shetty, MungliPrakash, Mohammed S Ibahim, -Relationship between free iron and glycated hemoglobin in uncontrolled type 2 diabetes patients associated with complicationsll. Indian Journal of clinical. Biochemistry, 2008; 23(1) 67-70.

Copyright: () the author(s), 2019. It is an open-access article distributed under the terms of the Creative Commons Attribution License (CC BY 4.0), which permits authors to retain ownership of the copyright for their content, and allow anyone to download, reuse, reprint, modify, distribute and/or copy the content as long as the original authors and source are cited.

How to cite this article: Ahmad T. Study of Serum Ferritin and Glycated Hemoglobin in Type 2 Diabetes Mellitus. Acad. J Med. 2019;2(2):28-31.

DOI: dx.doi.org/10.21276/ajm.2019.2.2.9

Source of Support: Nil, Conflict of Interest: None declared. 